\title{
First Record of the Monogenean Parasite of Menziesia sebastodis (Capsalidae) in Korea
}

\author{
Jeong-Ho Kim* \\ Faculty of Marine Bioscience and Technology, Kangnung National University,
} Gangneung 210-702, Korea

\begin{abstract}
Menziesia sebastodis (Capsalidae: Monogenea) is found and described from the gill filaments and the gill rakers of the black rockfish, Sebastes inermis, caught at Dolsan Island, off the south coast of Yeosu, Jeollanam-do, Korea. The genus Menziesia is distinguished from other related genera Benedenia, Megalobenedenia and Trochopus, by septate haptors and the morphology of copulatory organs. M. sebastodis can be differentiated from other Menziesia species by the longer and slenderer posterior anchor, and the location of accessory gland reservoir. This is the first record of the genus Menziesia in Korea.
\end{abstract}

Key words: Menziesia sebastodis, Monogenea, Capsalidae, Sebastes inermis

\section{INTRODUCTION}

The class monogenea belongs to the phylum Platyhelminthes and mostly parasitize on skins and gills of freshwater and marine fishes (Ogawa, 2005). They are equipped with a large attachment organ called 'haptor' at the posterior end. These groups are hermaphrodites and have direct life cycles. Generally they are not considered to cause serious pathological effects in wild fishes. However, in captive conditions, monogeneans can increase exponentially by direct life cycles and cause fatal damages to fishes, consequently.

Several monogeneans, known to be pathogenic to aquaculture fish species, are already reported in Korea (Choi et al., 1997; Kim and Cho, 2000). However, these approaches have mainly been restricted to pathology and treatment, and identification and morphological description have not been sufficient. This paper deals with morphological description of Menziesia sebastodis, a capsalid monogenean found on the gills of black rockfish, Sebastes inermis, in Korea.

\section{MATERIALS AND METHODS}

Sampling was conducted in offshore of Dolsan Island, Yeosu, Korea in 2007 and 2008. Wild black rockfish, Sebastes inermis were caught by stationary net. Live fish were kept in a container with seawater and immediately transported to the laboratory. Excessive amount of 2-phenoxyethanol (Sigma, USA) were used for euthanasia. Each individual fish was measured, weighed and dissected for parasitological

\footnotetext{
*To whom correspondence should be addressed

Tel: 82-33-640-2851, Fax: 82-33-640-2340

E-mail: jhkim70@kangnung.ac.kr
}

examination. Gills were excised and examined in filtered seawater under a dissecting microscope. If monogeneans were found, they were individually picked and immediately fixed with AFA (mixture of $70 \%$ ethanol 20 parts, formaldehyde $(40 \% \mathrm{w} / \mathrm{v}) 1$ part and glacial acetic acid 1 part), after flattening with cover glass. Monogenean specimens were stained with Heidenhein's hematoxylin, dehydrated through an alcohol series, and mounted in Canada balsam prior to examination. Drawings were made with the aid of a camera lucida. Measurements are given in millimeters.

\section{SYSTEMATIC ACCOUNTS}

Phylum Platyhelminthes Gegenbaur, 1859

Class Monogenea Carus, 1863

Order Capsalidea Lebedev, 1988

Family Capsalidae Baird, 1853

Subfamily Benedeninae Johnston, 1931

Genus Menziesia Gibson, 1976

\section{Menziesia sebastodis (Yamaguti, 1934) Whittington,} Deveney et Wyborn, 2001

Synonyms. Epibdella sebastodis Yamaguti, 1934; Benedenia sebastodis (Yamaguti, 1934) Meserve, 1938.

Type host. Sebastodes (now Sebastes) inermis (Scorpaenidae).

Type Locality. Ise Bay, Japan.

Site. Gills (gill filaments and gill rakers).

Distribution. Ise Bay, Japan (Yamaguti, 1934); Coast of Fukuoka Prefecture, Japan (Iwata, 1990); Dolsan Island, Yeosu, Korea (This study). 


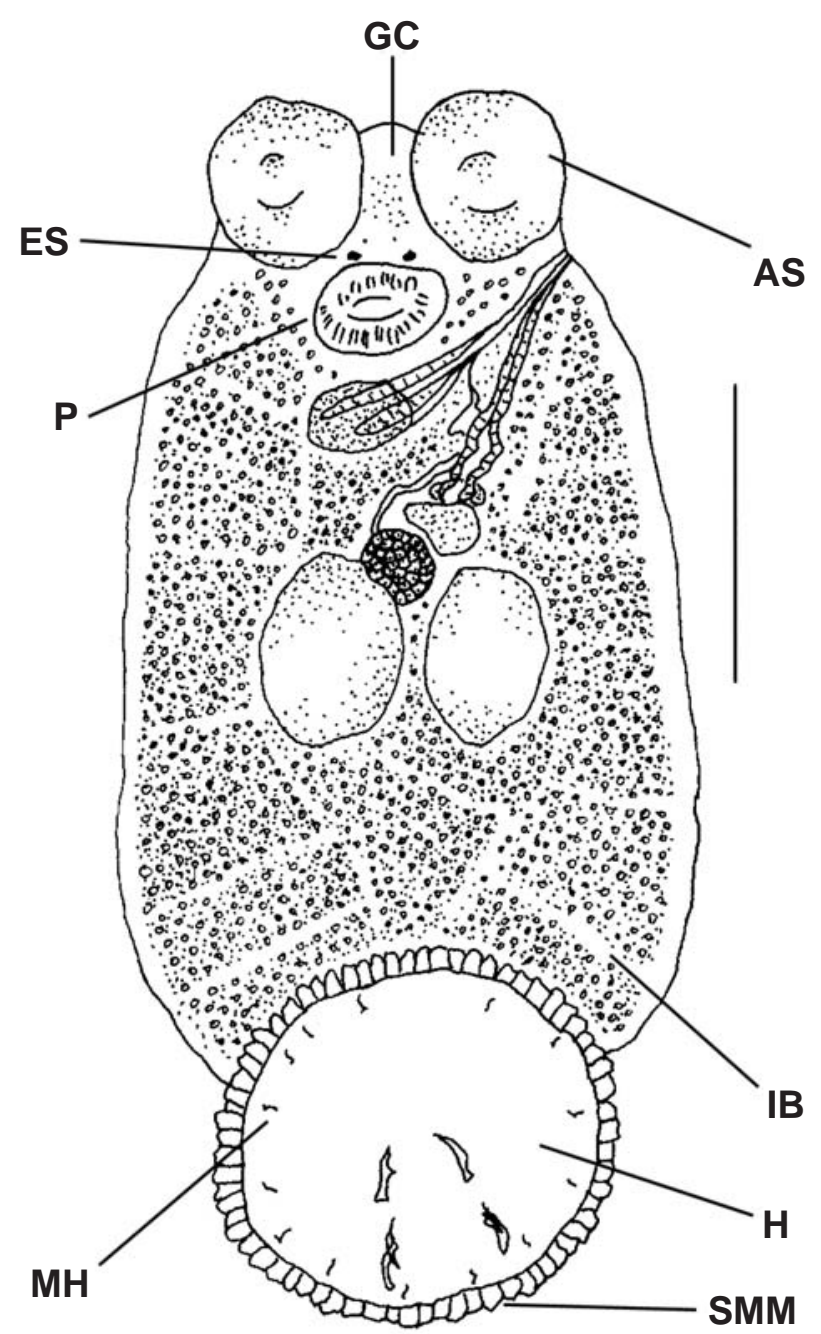

Fig. 1. Menziesia sebastodis (Yamaguti, 1934) Whittington, Deveney et Wyborn, 2001, Entire animal in ventral view. AS, anterior sucker; GC, gland cells; ES, eye spots; P, pharynx; IB, intestinal branches; $\mathrm{H}$, haptor; $\mathrm{MH}$, marginal hooklets; SMM, scalloped marginal membrane. Scale bar $=0.5 \mathrm{~mm}$.

Prevalence and intensity. At Dolsan Island, prevalence 75\% $(\mathrm{n}=20$ fish; total length $15.5-19.4 \mathrm{~cm})$ in $2007,100 \%(\mathrm{n}=21$ fish; total length $13.4-18.9 \mathrm{~cm}$ ) in 2008 ; intensity 1-8 in 2007, 1-11 in 2008.

Materials examined. 4 individuals (from Dolsan Island, Yeosu, Korea).

Description (Figs. 1-3). Body flattened and oval, 1.42-2.09 long with maximum width of 1.03-1.30 at the middle of body proper. Haptor disc-shaped, aseptate, entirely surrounded by scalloped marginal membrane, $0.59-0.66$ in diameter excluding the marginal membrane. 3 pairs of anchors and 7 pairs of marginal hooklets. Anterior anchor biramous root, flattened apex, 0.068-0.097 long, posterior anchor tined, 0.108-

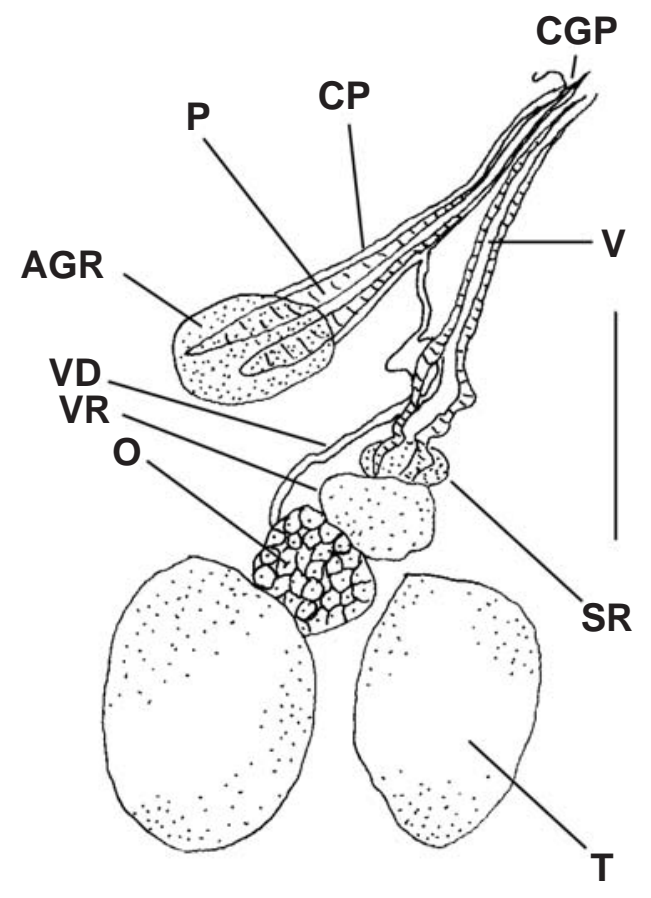

Fig. 2. Detailed reproductive system of $M$. sebastodis (Yamaguti, 1934) Whittington, Deveney et Wyborn, 2001. Ventral view. CGP, common genital pore; $C P$, cirrus pouch; $P$, penis; $V$, vagina; $A G R$, accessory gland reservoir; VD, vas deferens; $V R$, vitelline reservoir; $\mathrm{O}$, ovary; $\mathrm{SR}$, seminal receptacle; $\mathrm{T}$, testis. Scale bar $=0.25 \mathrm{~mm}$.

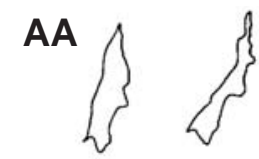

PA

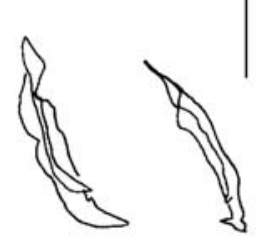

MH<smiles>CCCCCC(C)C</smiles>

Fig. 3. Morphology of anterior and posterior anchors. AA, anterior anchors; $\mathrm{PA}$, posterior anchors; $\mathrm{MH}$, marginal hooklets. Scale bar $=0.2 \mathrm{~mm}$.

0.193 long. A pair of suckers at the anterior end of body, ovoid, 0.22-0.29 long by 0.27-0.29 wide. 2 pairs of eyespots behind anterior suckers. Pharynx circular, 0.158-0.238 long 
by $0.215-0.293$ wide. Gland cells between the pharynx and the anterior suckers. Intestine ramified, terminating blindly.

Two testes ovoid, in the middle of body proper, 0.1940.287 long by $0.213-0.291$ wide. Vas deferens running alongside of ovary, vitelline reservoir and entering cirrus pouch. Accessory gland reservoir sigmoid, dorsal to the proximal end of penis. Penis, elongated, tapering distally, in weakly muscular capsule. Common genital pore opening near left side of body approximately at the level of pharynx. Ovary elliptical, in front of testes, 0.129-0.186 long by 0.162-0.197 wide. Seminal receptacle ovoid, 0.048-0.076 long by $0.101-$ 0.119 wide, anterior to vitelline reservoir. Vitelline reservoir irregular, 0.099-0.123 long by $0.131-0.145$ wide, anterior to ovary. Vagina long, muscular, with wide lumen proximally, opening dorsal or posterior to common genital pore. No eggs observed.

\section{DISCUSSION}

This is the first report of Menziesia sebastodis which belong to family capsalidae in Korea. They were found from black rockfish (Sebastes inermis) caught Dolsan Island, off the south coast of Yeosu, Korea. Although a few reports were already recorded for capsalid monogeneans in Korea (Choi et al., 1997; Kim et al., 1998), they were misdiagnosed or not properly identified as species level.

Classification of family Capsalidae at the subfamily level has been conducted by haptor morphology, number and arrangement of testis. According to these, the capsalidae are divided into 9 subfamilies with approximately 44-46 genera including 200 species (Whittington, 2004). Generally, the capsalid monogeneans are known as 'skin parasites', however, they can attach to many different tissues such as fins and gills. Of 9 subfamilies, only 2 subfamilies (Benedeniinae, Trochopodinae) includes the genera using gills as their microhabitats; Benedenia, Trochopus, Megalobenedenia, Menziesia (Yamaguti, 1934, 1969; Arai and Koski, 1964; Egorova, 1994a, b, 2000; Whittington et al., 2001).

The capsalidae is an unusual monogenean family because species extend across major fish groups as their hosts. For example, 15 species in five genera are known to parasitize elasmobranchs, and six genera for lutjanid fishes as their hosts (Whittington, 2004). In the same manner, at least six genera (Benedenia, Trochopus, Menziesia, Megalobenedenia, Megalocotyle, Megalocotyloides) are found from scorpaenid fishes (Egorova, 1994b).

Based on these information collectively, three genera are found to be the possible capsalid monogeneans from $S$. inermis in this study; Menziesia, Megalobenedenia, Trochopus. However, both of genera Megalobenedenia and Trochopus are distinguished from Menziesia by haptor morphology. They have a septate haptor, whereas Menziesia has an aseptate haptor. Capsalid monogeneans found in this study have an aseptate haptor. Hence, they were thought to belong to the genus Menziesia.

Genus Menziesia was erected by Gibson in 1976 with the characteristics of an elongate, tapering penis with a sigmoid accessory gland reservoir located alongside the proximal end of the penis. Another distinguishing character is a long muscular vagina with proximally wide rumen (Gibson, 1976). Genus Menziesia can be distinguished from the related genus Benedenia by penis morphology. Menziesia sebastodis was firstly described by Yamaguti (1934) as Benedenia sebastodis from Sebastes inermis and Iwata (1990) redescribed this monogenean parasite in detail. The measurements and the morphological characteristics of each anatomical parts of Menziesia species in this study closely resembles with those described by Iwata (1990). Recently Whittington et al. (2001) validated the genus Menziesia, after a rigorous taxonomic confusion, under the concept of morphological differences of copulatory organs. They transferred all the Benedenia species having an accessory gland reservoir located beside the proximal end of penis to the genus Menziesia. Therefore, Benedenia sebastodis was transferred to Menziesia Gibson, 1976 and the present specimens found in this study were identified as $M$. sebastodis.

There have been only two reports on capsalid monogeneans in Korea. Kim et al. (1998) described Benedenia derzhavini on the gills and gill operculum of Sebastes schlegeli. However, their description is questionable because $B$. derzhavini was transferred to a newly established genus Megalobenedenia in 1994, characterized by a septate haptor (Egorova, 1994a). Moreover, the monogeneans they described had an aseptate haptor, which is clearly different from that of Megalobenedenia. Choi et al. (1997) found Benedenia sp. on body surfaces of rock bream, Oplegnathus fasciatus, but they did not give any morphological description of the worms.

\section{ACKNOWLEDGEMENTS}

This work was supported by a grant from the Korean Research Foundation Grant (KRF-2005-070-C00124). The author wishes to thank Dr. S.-R. Kim and Prof. M.-J. Oh, Chonnam National University, for their kind helps in collecting fish, and Mr. D.-J. Jeon and Mr. Y.-S. Kim, Kangnung National University, for their assistance in collecting M. sebastodis.

\section{REFERENCES}

Arai, H.P. and C.H. Koski, 1964. A new species of Trochopus 
(Monogenea: Capsalidae) from Scorpaena guttata Girard. Can. J. Zool., 42: 1007-1010.

Choi, S.-D., Y.-G. Gong., J.-M. Paek and I.-C. Bang, 1997. Study on toxicity and extermination of monogenea, Benedenia sp. Parasite to culturing rock bream, Oplegnathus fasciatus in southern Korea. J. Aquaculture, 10: 1-7. (in Korean with English summary)

Egorova, T.P., 1994a. About new genus Megalobenedenia (Capsalidae: Trochopodinae). Parazitologia, 28: 76-78. (in Russian with English Summary)

Egorova, T.P., 1994b. A taxonomic review of the subfamily Trochopodinae (Monogenoidea: Capsalidae). Parazitologia, 28: 81-91. (in Russian with English Summary)

Egorova, T.P., 2000. New monogeneans of the genus Dionchus (Capsalidae: Dionchinae). Parazitologia, 34: 252-258. (in Russian with English Summary)

Gibson, D.I., 1976. Menziesia (Monogenea: Capsalidae), a new name for Parabenedenia Gibson, 1976 nec Johnston, 1929. J. Helminthol., 50: 98.

Iwata, K., 1990. Ectoparasitic trematodes from marine fishes of Kyusyu, Japan, I. The Family Capsalidae. Med. Bull. Fukuoka Univ., 1: 427-440.

Kim, K.-H. and S.-R. Kwon, 1998. Benedenia derzhavini (Trematoda: Monogenea) from cultured Korean rockfish, Sebastes schlegeli, in Korea. J. Fish Pathol., 11: 83-86.
Kim, K.-H. and J.-B. Cho, 2000. Treatment of Microcotyle sebastis (Monogenea: Polyopisthocotylea) infestation with praziquantel in an experimental cage simulating commercial rockfish Sebastes schlegeli culture conditions. Dis. Aquat. Org., 40: 229-231.

Ogawa, K., 2005. Parasitology of fishes in aquaculture. University of Tokyo Press, Tokyo, pp. 94-96. (in Japanese)

Whittington, I.D., M.R. Deveney and S.J. Wyborn, 2001. A revision of Benedenia Diesing, 1858 including a redescription of B. scianae (van Beneden, 1856) Odhner, 1905 and recognition of Menziesia Gibson, 1976 (Monogenea: Capsalidae). J. Nat. His., 35: 663-777.

Whittington, I.D., 2004. The capsalidae (Monogenea: Monopisthocotylea): A review of diversity, classification and phylogeny with a note about species complexes. Folia Parasitologica, 51: 109-122.

Yamaguti, S., 1934. Studies on the helminth fauna of Japan. Pt. 2. Trematodes of Fishes 1. Jpn. J. Zool., 5: 253-541.

Yamaguti, S., 1969. Systema Helminthum Vol. IV. Monogenea and Aspidocotylea. Interscience Publishers, New York, pp. 122-135. 